\title{
FAKTOR-FAKTOR YANG BERHUBUNGAN DENGAN KINERJA BIDAN DALAM PELAKSANAAN KEGIATAN DESA SIAGA DI KABUPATEN TAPIN
}

\author{
Suhrawardi ${ }^{1}$, Vonny Khresna Dewi ${ }^{2}$ \\ ${ }^{1,2}$ Poltekkes Kemenkes Banjarmasin Jurusan Kebidanan \\ Email: penelitian.poltekkes@gmail.com
}

\begin{abstract}
Related Factors with Midwives Performance in Activities of Alert Village at Tapin District. On the development of Alert Village in Tapin district is composed of 12 districts and has 132 villages, only 5 villages reached strata III (Alert Village Purnama) and 31 villages with strata II (Alert Village Madya) and only one village that has been with strata IV (Village standby Mandiri), while 50 others are still on the alert village strata I (alert Village Primary). The purpose of this study was to determine the factors related to the performance of midwives in the implementation of alert village in Tapin 2014. Population and sample in this research are all midwives working in Alert Village Tapin district in 2014 amounted to 62 people. The sampling technique was saturated sampling. Data analysis is quantitative data analysis: univariate, bivariate analysis using chi square test and analysis of qualitative data. The results showed that the performance of midwives who are active in the implementation of alert village as many as 40 people (64.5\%, mostly midwives Education Diploma III Midwifery many as 53 people (85.5\%), Age midwife mostly aged over 35 years as 43 people $(69.3 \%)$, midwife largely been trained as many as 38 people (61.3\%), most of the midwife has worked for more than five years as many as 44 people (71\%), there is a connection with the performance of midwives midwifery education in Alert Village implementation, there is a connection with the age midwife midwives performance in the implementation of alert village, there is a connection with the training of midwives in the implementation of performance prepared village, there was a significant association between long working performance in the implementation of alert village midwife in Tapin district.
\end{abstract}

Keywords: Performance, Midwives, Alert Village

\begin{abstract}
Abstrak: Faktor-Faktor yang Berhubungan dengan Kinerja Bidan dalam Pelaksanaan Kegiatan Desa Siaga di Kabupaten Tapin. Pada pengembangan Desa Siaga di Kabupaten Tapin terdiri dari 12 kecamatan dan mempunyai 132 desa, baru 5 desa yang mencapai strata III (Desa Siaga Purnama) dan 31 desa dengan strata II (Desa Siaga Madya) serta hanya 1 desa yang sudah dengan strata IV (Desa Siaga Mandiri), sedangkan 50 Desa Siaga lainya masih pada strata I (Desa Siaga Pratama). Tujuan penelitian ini adalah untuk mengetahui faktor-faktor yang berhubungan dengan kinerja bidan dalam pelaksanaan kegiatan Desa Siaga di Kabupaten Tapin tahun 2014. Jenis penelitian survey analitik dengan pendekatan cross sectional. Populasi dan sampel penelitian ini adalah seluruh bidan yang bekerja di Desa Siaga Kabupaten Tapin tahun 2014 berjumlah 62 orang. Teknik pengambilan sampel adalah sampling jenuh. Teknik analisa data adalah analisis data Kuantitatif : univariat, bivariat dengan menggunakan uji chi square dan analisis data kualitatif. Hasil penelitian menunjukkan bahwa kinerja bidan yang aktif dalam pelaksanaan kegiatan Desa Siaga sebanyak 40 orang $(64,5 \%)$, Pendidikan bidan sebagian besar lulusan D-III Kebidanan sebanyak 53 orang $(85,5 \%)$, Umur bidan sebagian besar berusia di atas 35 tahun sebanyak 43 orang $(69,3 \%)$, Bidan sebagian besar telah mengikuti pelatihan sebanyak 38 orang $(61,3 \%)$, Bidan sebagian besar telah bekerja lebih dari 5 tahun sebanyak 44 orang $(71 \%)$, ada hubungan pendidikan bidan dengan kinerja bidan dalam pelaksanaan Desa Siaga, ada hubungan umur bidan dengan kinerja bidan dalam pelaksanaan Desa Siaga, ada hubungan pelatihan dengan kinerja bidan dalam pelaksanaan Desa Siaga, ada hubungan yang bermakna antara lama bekerja dengan kinerja bidan dalam pelaksanaan Desa Siaga di Kabupaten Tapin.
\end{abstract}

Kata kunci : Kinerja, Bidan, Desa siaga

Desa Siaga merupakan salah satu sasaran dari tiga sasaran Grand Strategy Departemen Kesehatan, yang menyebutkan bahwa pada akhir tahun 2008, seluruh desa telah menjadi Desa siaga, yaitu desa yang memiliki kesiapan sumber daya serta kemauan dan kemampuan untuk mencegah dan mengatasi masalah-masalah 
kesehatan, bencana dan kegawatdaruratan kesehatan secara mandiri ( Depkes RI, 2008).

Program pengembangan Desa Siaga sebagai program yang berbasis pemberdayaan masyarakat. Sejak dikembangkannya Desa Siaga pada tahun 2006 sampai tahun 2009 telah terbentuk $42.295(56,1 \%)$ dari 75.410 Desa yang ada. Namun diantaranya masih belum berhasil menciptakan Desa Siaga aktif yang sesungguhnya. (Depkes, 2010).

Pada pengembangan Desa Siaga, tenaga kesehatan yang banyak berperan adalah bidan desa, karena bidan di desa merupakan tenaga kesehatan yang paling dekat dengan masyarakat karena mereka tinggal bersama masyarakat serta bidan saat ini sebagai satu-satunya tenaga kesehatan yang berada pada lini terdepan dan melaksanakan hampir semua program kesehatan yang ada di tingkat desa.

Pengembangan Desa Siaga, peran bidan adalah sebagai; pembimbing dan pelaksana penggerakan dan pemberdayaan masyarakat melalui kemitraan, pembimbing dan pelaksana pelayanan kegawatdaruratan kesehattan seharihari serta bencana, pembimbing dan pelaksana tanggap darurat bencana serta pelaksana pelayanan medis dasar sesuai dengan kompetensi dan wewenangnya.

Kabupaten Tapin terdiri dari 12 kecamatan dan mempunyai 75 desa, dengan jumlah bidan sebanyak 98 orang. Sejak dicanangkannya program Desa Siaga oleh Menteri Kesehatan pada Nopember 2006, sampai pada akhir 2013 sudah terbentuk 62 Desa Siaga $(82,66 \%)$. Pada pengembangan Desa Siaga, baru 5 desa yang mencapai strata III (Desa Siaga Purnama) dan 31 desa dengan strata II (Desa Siaga Madya) serta hanya 1 desa yang sudah dengan strata IV (Desa Siaga Mandiri), sedangkan 26 Desa Siaga lainya masih pada strata I (Desa Siaga Pratama) (Dinkes Tapin, 2013). Data tersebut menunjukkan bahwa pengembangan strata Desa Siaga tidak merata pada tiap desa, sebagai penanggung jawab Desa Siaga, keaktifan kinerja Bidan dalam pengembangan Desa Siaga sangat diharapkan.

Berdasarkan data tersebut penelti tertarik untuk melakukan penelitian tentang Faktorfaktor yang berhubungan dengan kinerja Bidan dalam pelaksanaan kegiatan Desa Siaga di Kabupaten Tapin Tahun 2014.

\section{METODE PENELITIAN}

Penelitian ini termasuk jenis penelitian penelitian survey analitik dengan pendekatan cross sectional. Instrumen penelitian dengan menggunakan kuesioner untuk data variabel independen (pendidikan, umur, pelatihan dan lama bekerja) serta menggunakan panduan Indepht Interview (wawancara mendalam) untuk data variabel dependen (kinerja bidan).

Populasi penelitian ini adalah seluruh bidan yang bekerja di Desa Siaga Kabupaten Tapin tahun 2014, berjumlah 62 orang. Sampel penelitian ini adalah seluruh bidan yang bekerja di Desa Siaga Kabupaten Tapin tahun 2014, berjumlah 62 orang.. Teknik pengambilan sampel secara sampling jenuh. Variabel independen (pendidikan, umur, pelatihan dan lama bekerja) serta menggunakan panduan Indepht Interview (wawancara mendalam) untuk variabel dependen (kinerja bidan). Analisis data dengan analisis data kuantitatif dlakukan dengan tahapan sebagai berikut : 1) Analisis univariat, 2) Analisis bivariat menggunakan uji chi square dan Fisher's Exact serta Analisis data kualitatif melalui beberapa tahapan, yaitu sebagai berikut : 1) Mentranskrip, 2) Mengkoding data, 3) Mengkategorikan data (open codes), 4) Melakukan core kategori, 5) Mengeksplorasi hubungan antara core kategori (tema), 6) Menarik kesimpulan dan verifikasi

\section{HASIL}

\section{A. ANALISIS UNIVARIAT}

\section{Kinerja Bidan}

Tabel 1. Distribusi Frekuensi Responden Berdasarkan Kinerja Bidan Pada Pelaksanaan Kegiatan Desa Siaga

\begin{tabular}{crr}
\hline Kinerja Bidan & Jumlah & \multicolumn{1}{c}{$\%$} \\
\hline Aktif & 40 & 64.5 \\
\hline Tidak Aktif & 22 & 35.5 \\
\hline Jumlah & 62 & 100.0 \\
\hline
\end{tabular}

\section{Sumber: Data Primer}

Pada tabel 1 dapat dilihat, bahwa dari 62 orang bidan yang bekerja di Desa Siaga, menunjukkan kinerja aktif pada pelaksanaan kegiatan Desa Siaga berjumlah 40 orang $(64.5 \%)$ 


\section{Pendidikan Bidan}

Tabel 2. Distribusi Frekuensi Responden Berdasarkan Pendidikan Bidan

\begin{tabular}{lrr}
\hline Pendidikan Bidan & Jumlah & \% \\
\hline Diploma IV & 9 & 14.5 \\
\hline Diploma III & 53 & 85.5 \\
\hline \multicolumn{1}{c}{ Jumlah } & 62 & 100.0 \\
\hline
\end{tabular}

Sumber: Data Primer

Tabel 2 menunjukkan, bahwa dari 62 orang bidan yang bekerja di Desa Siaga, 53 orang $(85.5 \%)$ berpendidikan Diploma III Kebidanan.

\section{Umur Bidan}

Tabel 3. Distribusi Frekuensi Responden Berdasarkan Umur Bidan

\begin{tabular}{ccc}
\hline Umur Bidan & Jumlah & \% \\
\hline Di atas 35 tahun & 43 & 69.3 \\
\hline Di bawah 35 tahun & 19 & 30.7 \\
\hline Jumlah & 62 & 100.0 \\
\hline
\end{tabular}

Sumber: Data Primer

Pada tabel 3 dapat dilihat, bahwa dari 62 orang bidan yang bekerja di Desa Siaga, 42 orang $(67.7 \%)$ berumur di atas 35 tahun.

\section{Pelatihan Bidan}

Tabel 4. Distribusi Frekuensi Responden Berdasarkan Pelatihan Desa Siaga

\begin{tabular}{lrc}
\hline Pelatihan Desa Siaga & Jumlah & \% \\
\hline Mengikuti pelatihan & 38 & 61.3 \\
\hline $\begin{array}{l}\text { Tidak mengikuti } \\
\text { pelatihan }\end{array}$ & 24 & 38.7 \\
\hline \multicolumn{1}{c}{ Jumlah } & 62 & 100.0 \\
\hline
\end{tabular}

Sumber : Data Primer

Pada tabel 4 dapat dilihat, bahwa dari 62 orang bidan yang bekerja di Desa Siaga, 38 orang $(61.3 \%)$ sudah mengikuti pelatihan tentang Desa Siaga.

\section{Lama Bekerja}

Tabel 5. Distribusi Frekuensi Responden Berdasarkan Lama Bekerja

Lama Bekerja Jumlah \%

\begin{tabular}{crr}
\hline Di atas 5 tahun & 44 & 71 \\
\hline Di bawah 5 tahun & 18 & 29 \\
\hline Jumlah & 62 & 100.0
\end{tabular}

Sumber : Data Primer

3.
Tabel 5 menunjukkan, bahwa dari 62 orang bidan yang bekerja di Desa Siaga, 44 orang (71\%) bekerja lebih dari 5 tahun.

\section{B. ANALISIS BIVARIAT}

1. Hubungan Pendidikan Bidan dengan Kinerja Bidan dalam pelaksanaan kegiatan Desa Siaga

Tabel 6. Hubungan Pendidikan Bidan dengan Kinerja Bidan dalam Pelaksanaan Kegiatan Desa Siaga

\begin{tabular}{crrrrrr}
\hline \multirow{2}{*}{$\begin{array}{c}\text { Pendidikan } \\
\text { Bidan }\end{array}$} & \multicolumn{4}{c}{ Kinerja Bidan } & \multicolumn{2}{c}{ Total } \\
\cline { 2 - 6 } & \multicolumn{1}{c}{ Aktif } & \multicolumn{3}{c}{$\begin{array}{c}\text { Tidak } \\
\text { Aktif }\end{array}$} & \multirow{5}{*}{$f$} & $\%$ \\
\cline { 2 - 6 } & $\boldsymbol{f}$ & $\boldsymbol{\%}$ & $\boldsymbol{f}$ & $\boldsymbol{\%}$ & & \\
\hline Diploma IV & 9 & 100,0 & 0 & 0 & 9 & 100 \\
\hline Diploma III & 31 & 58,5 & 22 & 41,6 & 53 & 100 \\
\hline Total & 40 & 64,5 & 22 & 35,3 & 62 & 100 \\
\hline Uji Fisher's Exact & $p: 0,016$ & & & \\
\hline
\end{tabular}

Pada tabel 6 dapat dilihat, bahwa dari 9 orang bidan yang berpendidikan Diploma IV, 9 orang bidan (100\%) yang aktif dalam pelaksanaan kegiatan Desa Siaga, dan dari 53 orang bidan yang berpendidikan Diploma III, 31 orang bidan $(58,5 \%)$ yang aktif dalam pelaksanaan kegiatan Desa Siaga.

Hasil uji statistik dengan Fisher's Exact dengan nilai $\alpha: 0,05$ didapatkan nilai $p: 0,016$, berarti ada hubungan yang bermakna antara pendidikan bidan dengan kinerja bidan dalam pelaksanaan kegiatan Desa Siaga di Kabupaten Tapin Tahun 2014.

2. Hubungan Umur Bidan dengan Kinerja Bidan dalam pelaksanaan kegiatan Desa Siaga

Tabel 7. Hubungan Umur Bidan dengan Kinerja Bidan dalam Pelaksanaan Kegiatan Desa Siaga

\begin{tabular}{|c|c|c|c|c|c|c|}
\hline \multirow{3}{*}{$\begin{array}{l}\text { Umur } \\
\text { Bidan }\end{array}$} & \multicolumn{4}{|c|}{ Kinerja Bidan } & \multicolumn{2}{|c|}{ Total } \\
\hline & \multicolumn{2}{|c|}{ Aktif } & \multicolumn{2}{|c|}{ Tidak Aktif } & \multirow{2}{*}{$f$} & \multirow{2}{*}{$\%$} \\
\hline & $f$ & $\%$ & $f$ & $\%$ & & \\
\hline $\begin{array}{l}\text { Di atas } \\
35 \text { tahun }\end{array}$ & 37 & 86,0 & 6 & 14,0 & 43 & 100 \\
\hline $\begin{array}{l}\text { Di bawah } \\
35 \text { tahun }\end{array}$ & 3 & 15,8 & 16 & 84,2 & 19 & 100 \\
\hline Total & 40 & 64,5 & 22 & 35,5 & 62 & 100 \\
\hline
\end{tabular}

Pada tabel 7 dapat dilihat, bahwa dari 43 orang bidan yang berumur di atas 35 tahun, 37 orang bidan $(86,0 \%)$ yang aktif dalam 
pelaksanaan kegiatan Desa Siaga, dan dari 19 orang bidan yang berumur di bawah 35 tahun, 3 orang bidan $(15,8 \%)$ yang aktif dalam pelaksanaan kegiatan Desa Siaga.

Hasil uji statistik dengan Fisher's Exact dengan nilai $\alpha: 0,05$ didapatkan nilai $p: 0,000$, berarti ada hubungan yang bermakna antara umur bidan dengan kinerja bidan dalam pelaksanaan kegiatan Desa Siaga di Kabupaten Tapin Tahun 2014.

\section{Hubungan Pelatihan dengan Kinerja Bidan dalam pelaksanaan kegiatan Desa Siaga}

Tabel 8. Hubungan Pelatihan dengan Kinerja Bidan dalam Pelaksanaan Kegiatan Desa Siaga

\begin{tabular}{|c|c|c|c|c|c|c|}
\hline \multirow{3}{*}{$\begin{array}{l}\text { Pelatihan } \\
\text { Desa Siaga }\end{array}$} & \multicolumn{4}{|c|}{ Kinerja Bidan } & \multicolumn{2}{|c|}{ Total } \\
\hline & \multicolumn{2}{|c|}{ Aktif } & \multicolumn{2}{|c|}{$\begin{array}{l}\text { Tidak } \\
\text { Aktif }\end{array}$} & \multirow[t]{2}{*}{$f$} & \multirow[t]{2}{*}{$\%$} \\
\hline & $f$ & $\%$ & $f$ & $\%$ & & \\
\hline Mengikuti & 38 & 100,0 & 0 & 0 & 38 & 100 \\
\hline $\begin{array}{l}\text { Tidak } \\
\text { mengikuti }\end{array}$ & 2 & 8,3 & 22 & 91,7 & 24 & 100 \\
\hline Total & 40 & 64,5 & 22 & 35,5 & 62 & 100 \\
\hline Uji Fisher' & $a c t$ & $p: 0$ & & & & \\
\hline
\end{tabular}

Pada tabel 8 dapat dilihat, bahwa dari 38 orang bidan yang mengikuti pelatihan Desa Siaga, 38 orang bidan $(100 \%)$ yang aktif dalam pelaksanaan kegiatan Desa Siaga, dan dari 24 orang bidan yang tidak mengikuti pelatihan Desa Siaga, hanya 2 orang bidan $(8,3 \%)$ yang aktif dalam pelaksanaan kegiatan Desa Siaga.

Hasil uji statistik dengan Fisher's Exact dengan nilai $\alpha: 0,05$ didapatkan nilai $p: 0,000$, berarti ada hubungan yang bermakna antara pelatihan Desa Siaga dengan kinerja bidan dalam pelaksanaan kegiatan Desa Siaga di Kabupaten Tapin Tahun 2014.

\section{Hubungan Lama Bekerja dengan Kinerja Bidan dalam pelaksanaan kegiatan Desa Siaga}

Pada tabel 9 dapat dilihat, bahwa dari 44 orang bidan yang bekerja di atas 5 tahun, 38 orang bidan $(86,4 \%)$ yang aktif dalam pelaksanaan kegiatan Desa Siaga, dan dari 18 orang bidan yang bekerja di bawah 5 tahun, 2 orang bidan $(11,1 \%)$ yang aktif dalam pelaksanaan kegiatan Desa Siaga.

Hasil uji statistik dengan Fisher's Exact dengan nilai $\alpha: 0,05$ didapatkan nilai $p: 0,000$, berarti ada hubungan yang bermakna antara lama bekerja dengan kinerja bidan dalam pelaksanaan kegiatan Desa Siaga di Kabupaten Tapin Tahun 2014.

Tabel 9. Hubungan Lama Bekerja dengan Kinerja Bidan dalam Pelaksanaan Kegiatan Desa Siaga

\begin{tabular}{|c|c|c|c|c|c|c|}
\hline \multirow{3}{*}{$\begin{array}{c}\text { Lama } \\
\text { Bekerja }\end{array}$} & \multicolumn{4}{|c|}{ Kinerja Bidan } & \multicolumn{2}{|c|}{ Total } \\
\hline & \multicolumn{2}{|c|}{ Aktif } & \multicolumn{2}{|c|}{$\begin{array}{l}\text { Tidak } \\
\text { Aktif }\end{array}$} & \multirow{2}{*}{$f$} & \multirow[t]{2}{*}{$\%$} \\
\hline & $f$ & $\%$ & $f$ & $\%$ & & \\
\hline $\begin{array}{l}\text { Di atas } 5 \\
\text { tahun }\end{array}$ & 38 & 86,4 & 6 & 13,6 & 44 & 100 \\
\hline $\begin{array}{l}\text { Di bawah } \\
5 \text { tahun }\end{array}$ & 2 & 11,1 & 16 & 88,9 & 18 & 100 \\
\hline Total & 40 & 64,5 & 22 & 35,5 & 64 & 100 \\
\hline
\end{tabular}

\section{PEMBAHASAN}

\section{Kinerja Bidan}

Berdasarkan hasil penelitian, bahwa dari 62 orang bidan yang bekerja di Desa Siaga, menunjukkan kinerja aktif pada pelaksanaan kegiatan Desa Siaga berjumlah 40 orang $(64.5 \%)$,

Sebagian besar bidan sudah melaksanakan kegiatan-kegiatan Desa Siaga dengan baik, hal ini dapat dinilai dari peran aktif bidan dalam melakukan sosialisasi program Desa Siaga, memberikan pelayanan di Poskesdes seperti pelayanan KIA-KB maupun pelayanan pengobatan dasar, kegiatan Posyandu, surveilans, ambulan desa dan kelompok donor darah, tabulin, penyuluhan, kebersihan lingkungan dan pencatatan pelaporan serta kegiatan penanggulangan bencana.

Peran bidan di desa sebagai pemberi pelayanan kesehatan pada masyarakat di wilayahnya diharapkan dapat dilaksanakan dengan aktif sesuai dengan kompetensi dan kewenangannya. Hasil penelitian menunjukkan bahwa pemberian pelayanan kesehatan oleh bidan di Poskesdes dilakukan dengan aktif, meliputi pelayanan penyuluhan, pemeriksaan ibu hamil, pelayanan $\mathrm{KB}$, pemberian imunisasi kepada bayi dan ibu hamil serta pemberian pelayanan pengobatan penyakit dan pertolongan persalinan. Pelayanan di Poskesdes tersebut dilakukan bidan setiap saat, bidan siap berada di Poskesdes untuk memberikan pelayanan 24 jam kepada masyarakat desa, karena semua bidan tinggal di desa dan menjadikan Poskesdes sebagai tempat tinggal. Pelayanan tidak hanya di Poskesdes saja, tetapi juga di luar Poskesdes, yaitu dengan mendatangi pasien ke rumah, meski tempatnya relatif jauh atau pada waktunya pada malam hari. 
Misi dari pembangunan kesehatan adalah "membuat rakyat sehat" yang akan dicapai melalui strategi, salah satunya adalah meningkatkan akses masyarakat terhadap pelayanan yang berkualitas, oleh karena itu peran aktif bidan dalam memberikan pelayanan kesehatan kepada masyarakat di desa sangat diharapkan, agar terwujudnya kesehatan bagi masyarakat desa. Menurut Depkes (2002) bidan dalam menjalankan praktik harus aktif membantu program pemerintah untuk meningkatkan derajat kesehatan masyarakat, khususnya dalam memberikan pelayanan kesehatan ibu dan anak serta keluarga berencana sesuai dengan kewenangan yang diberikan dan standar profesi yang ditetapkan.

Ketidakaktifan bidan dalam memberikan pelayanan kesehatan kepada masyarakat di desa binaannya dapat mempengaruhi keberhasilan pemberdayaan masyarakat di bidang kesehatan, karena menyebabkan masyarakat menjadi enggan untuk berpartisipasi aktif dalam upaya kesehatan yang dilaksanakan. Hal ini sesuai dengan penelitian Istiarti (1996) tentang peran bidan desa, bahwa faktor yang dominan dalam mempengaruhi penerimaan oleh masyarakat adalah keterampilan dan keaktifan serta sikap personalitas bidan dalam memberikan pelayanan kepada masyarakat. Keaktifan bidan dalam memberikan pelayanan kepada masyarakat, akan menumbuhkan dan meningkatkan kepercayaan masyarakat kepada petugas, sehingga dapat mendorong mereka untuk berpartisipasi pada upaya yang dilaksanakan.

\section{Pendidikan Bidan}

Hasil penelitian menunjukkan bahwa dari 62 orang bidan yang bekerja di Desa Siaga, 53 orang $(85.5 \%)$ berpendidikan Diploma III Kebidanan. Bidan yang berpendidikan Diploma III lebih banyak dikarenakan adanya peraturan bahwa yang disebut bidan profesional adalah bila pendidikannya minimal Diploma III sehingga saat itu untuk mencapai akselerasi tersebut ada beberapa Institusi pendidikan yang melaksanakan program pendidikan Diploma III sedangkan untuklbidan yang berpendidikan Diploma IV masih sedikit dikarenakan saat ini Institusi pendidikan untuk program Diploma IV hanya menerima dari lulusan SMU (0 Tahun) bukan lagi yang berasal dari alih jenjang seperti dulu, kalaupun mau melanjutkan program Diploma IV harus ke Luar Propinsi yang tentunya perlu pertimbangan khusus.

Menurut Robbins (2001) Kemampuan intelektual atau fisik khusus yang diperlukan untuk kinerja yang memadai pada suatu pekerjaan, bergantung pada persyaratan kemampuan yang diminta dari pekerjaan itu. Persyaratan kemampuan ini biasanya diakui apabila seorang individu telah melewati jenjang pendidikan tertentu. Secara umum kemampuan individu akan meningkat sesuai dengan jenjang pendidikan yang telah dilaluinya, selain itu bidan dalam menjalankan praktik mandiri harus berpendidikan minimal Diploma III Kebidanan (Kemenkes, 2010).

\section{Umur Bidan}

Hasil penelitian menunjukkan bahwa dari 62 orang bidan yang bekerja di Desa Siaga, 42 orang $(67.7 \%)$ berumur di atas 35 tahun. Hal ini terjadi karena saat pertama kali menjadi bidan rata rata umurnya masih relatif muda sehingga kalau dihitung sampai saat ini tentunyasudah lama mereka menjadi bidan. Selain itu juga mereka sudah merasa nyaman tinggal di desa wilayah kerjanya berbaur dengan masyarakat. Hurlock (1993) semakin cukup umur, tingkat kematangan dan kekuatan seseorang akan lebih matang dalam berpikir dan bekerja.

\section{Pelatihan Desa Siaga}

Hasil penelitian menunjukkan bahwa dari 62 orang bidan yang bekerja di Desa Siaga, 38 orang $(61.3 \%)$ sudah mengikuti pelatihan tentang Desa Siaga.

Pelatihan Program Desa Siaga merupakan bekal pengetahuan dan keterampilan bidan untuk melaksanakan kegiatan Desa Siaga, untuk itu pelatihan perlu dikuti oleh semua bidan yang bekerja pada Desa Siaga, agar mereka mempunyai pengetahuan dan keterampilan tentang kegiatan-kegiatan yang dilaksanakan pada program Desa Siaga.

Menurut Soetomo (2006), agar dapat melaksanakan tugas pelayanan sosial dengan baik dibutuhkan petugas yang profesional, atau paling tidak dibekali dengan pengetahuan dan skill yang cukup di bidang pelayanan sosial. Untuk maksud tersebut dibutuhkan adanya pelatihan bagi mereka, sehingga mereka menguasai metode dan pendekatan yang dibutuhkan serta mempunyai kemampuan untuk berkomunikasi secara baik dengan klien atau kelompok sasaran. Lebih dari itu, di samping bekal pengetahuan dan skill di bidang kesejahteraan dan pelayanan social.

\section{Lama Bekerja}

Hasil penelitian menunjukkan bahwa dari 62 orang bidan yang bekerja di Desa Siaga, 44 orang $(71 \%)$ bekerja lebih dari 5 tahun. Hal ini juga berkaitan dengan lamanya mereka menjadi bidan sehingga berpengaruh dengan masa 
kerjanya. Masa kerja seseorang juga menunjukkan hubungan secara positif terhadap kinerja seseorang. Masa kerja yang lama menunjukkan pengalaman yang lebih seseorang dibandingkan rekan kerja yang lain, sehingga sering masa kerja/pengalaman kerja menjadi pertimbangan suatu perusahaan dalam mencari pegawai (Robbins, 2001).

\section{Hubungan Pendidikan dengan Kinerja Bidan dalam Pelaksanaan Kegiatan Desa Siaga}

Hasil penelitian menunjukkan bahwa ada hubungan yang bermakna antara pendidikan dengan kinerja bidan dalam pelaksanaan kegiatan Desa Siaga. Menurut YB Mantra yang dikutip Notoatmodjo (2003), pendidikan dapat mempengaruhi seseorang termasuk juga perilaku seseorang akan pola hidup terutama dalam memotivasi untuk sikap berperan serta dalam pembangunan. Menurut Robbins (2001) Kemampuan intelektual atau fisik khusus yang diperlukan untuk kinerja yang memadai pada suatu pekerjaan, bergantung pada persyaratan kemampuan yang diminta dari pekerjaan itu. Persyaratan kemampuan ini biasanya diakui apabila seorang individu telah melewati jenjang pendidikan tertentu. Secara umum kemampuan individu akan meningkat sesuai dengan jenjang pendidikan yang telah dilaluinya, selain itu bidan dalam menjalankan praktik mandiri harus berpendidikan minimal Diploma III Kebidanan (Kemenkes, 2010).

\section{Hubungan Umur dengan Kinerja Bidan dalam Pelaksanaan Kegiatan Desa Siaga}

Hasil penelitian menunjukkan bahwa ada hubungan yang bermakna antara umur dengan kinerja bidan dalam pelaksanaan kegiatan Desa Siaga. Menurut Hurlock (1993) semakin cukup umur, tingkat kematangan dan kekuatan seseorang akan lebih matang dalam berpikir dan bekerja. Dari segi kepercayaan masyarakat seseorang yang lebih dewasa dipercaya dari orang yang belum tinggi kedewasaannya. Usia mempengaruhi terhadap daya tangkap dan pola pikir seseorang. Semakin bertambah usia akan semakin berkembang pula daya tangkap dan pola pikirnya, sehingga pengetahuan yang diperolehnya semakin membaik. Pada usia madya, individu akan lebih berperan aktif dalam masyarakat dan kehidupan sosial serta lebih baik banyak melakukan persiapan demi suksesnya upaya menyesuaikan diri menuju usia tua.

\section{Hubungan Pelatihan dengan Kinerja Bidan dalam Pelaksanaan Kegiatan Desa Siaga}

Hasil penelitian menunjukkan bahwa ada hubungan yang bermakna antara pelatihan dengan kinerja bidan dalam pelaksanaan kegiatan Desa Siaga. Depertemen Kesehatan membuat program pelatihan untuk bidan kesehatan agar bidan-bidan kesehatan desa siaga nantinya mempunyai pengetahuan yang lebih. Dengan harapan bidan dapat menggerakkan dan memberdayakan masyarakat agar tercipta masyarakat yang mandiri untuk hidup terutama pada kesehatan ibu dan anak guna mencapai penurunan AKI dan AKB di Indonesia (Syafrudin \& hamidah, 2007). Menurut Soetomo (2006), agar dapat melaksanakan tugas pelayanan sosial dengan baik dibutuhkan petugas yang profesional, atau paling tidak dibekali dengan pengetahuan dan skill yang cukup di bidang pelayanan sosial. Untuk maksud tersebut dibutuhkan adanya pelatihan bagi mereka, sehingga mereka menguasai metode dan pendekatan yang dibutuhkan serta mempunyai kemampuan untuk berkomunikasi secara baik dengan klien atau kelompok sasaran. Lebih dari itu, di samping bekal pengetahuan dan skill di bidang kesejahteraan dan pelayanan social, khususnya pada pelaksanaan Desa Siaga.

\section{Hubungan Lama Bekerja dengan Kinerja Bidan dalam Pelaksanaan Kegiatan Desa Siaga}

Hasil penelitian menunjukkan bahwa ada hubungan yang bermakna antara lama bekerja dengan kinerja bidan dalam pelaksanaan kegiatan Desa Siaga. Kinerja bidan dalam penampilan adalah hasil kerja personal baik kuantitas maupun kualitas dalam suatu organisasi. Kinerja dapat merupakan penampilan individu maupun kelompok kerja personal. Kinerja pada desa siaga dapat dihubungkan dengan beberapa faktor antara lain tingkat pendidikan, tingkat pengetahuan serta pengalaman dari personal masing-masing (Azwar, 2003). Bidan sebagai petugas kesehatan yang tinggal dan bekerja di desa sangat penting peranannya dalam reformasi pembangunan kesehatan desa, yaitu sebagai fasilitator pada upaya pemberdayaan masyarakat agar tujuan dari program Desa Siaga dapat tercapai.

\section{SIMPULAN}

Berdasarkan hasil penelitian terhadap 62 orang bidan tentang Faktor-faktor yang berhubungan dengan kinerja bidan pada pelaksanaan Desa Siaga di Kabupaten Tapin 
Tahun 2014, maka dapat disimpulkan sebagai berikut:

1. Kinerja bidan yang aktif dalam pelaksanaan kegiatan Desa Siaga sebanyak 40 orang $(64,5 \%)$. Pendidikan bidan di Desa Siaga Kabupaten Tapin, sebagian besar lulusan Diploma III Kebidanan, sebanyak 53 orang $(85,5 \%)$.

2. Umur bidan di Desa Siaga Kabupaten Tapin, sebagian besar berusia di atas 35 tahun, sebanyak 43 orang $(69,3 \%)$. Bidan di Desa Siaga Kabupaten Tapin, sebagian besar telah mengikuti pelatihan tentang Desa Siaga, sebanyak 38 orang $(61,3 \%)$.

3. Bidan di Desa Siaga Kabupaten Tapin, sebagian besar telah bekerja lebih dari 5 tahun, sebanyak 44 orang $(71 \%)$.

4. Ada hubungan yang bermakna antara pendidikan bidan dengan kinerja bidan dalam pelaksanaan Desa Siaga di Kabupaten Tapin. Ada hubungan yang bermakna antara umur bidan dengan kinerja bidan dalam pelaksanaan Desa Siaga di Kabupaten Tapin. Ada hubungan yang bermakna antara

\section{DAFTAR PUSTAKA}

Azwar, Syaifuddin. 2003. Sikap Manusia, Teori dan Pengukurannya. Yogyakarta: Pustaka Pelajar.

Departemen Kesehatan RI. 2008. Petunjuk Teknis Penggerakan dan Pemberdayaan Masyarakat dalam Pengembangan Desa Siaga. Jakarta.

Departemen Kesehatan RI. 2010. Pengembangan Desa dan Kelurahan Siaga Aktif. Jakarta.

Dinas Kesehatan Kabupaten Tapin. 2013. Profil Kesehatan Kabupaten Tapin Tahun 2013.

Hurlock,E.B. 1993. Psikologi Perkembangan: Suatu pendekatan sepanjang rentang pelatihan dengan kinerja bidan dalam pelaksanaan Desa Siaga di Kabupaten Tapin. Ada hubungan yang bermakna antara lama bekerja dengan kinerja bidan dalam pelaksanaan Desa Siaga di Kabupaten Tapin.

\section{SARAN}

1. Bagi bidan diharapkan agar lebih termotivasi untuk aktif dalam kegiatan-kegiatan Desa Siaga yang dilaksanakan di wilayah kerjanya, sesuai dengan tupoksinya.

2. Bagi Puskesmas diharapkan lebih meningkatkan pengawasan dan pembinaan secara berkelanjutan terhadap bidan-bidan yang bekerja di wilayah kerjanya, khususnya dalam pelaksanaan Desa Siaga.

3. Bagi Dinas Kesehatan diharapkan dapat membantu dalam menyediakan sarana dan parasarana serta mengikut-sertakan bidanbidan untuk mengikuti pelatihan-pelatihan khususnya dalam program Desa Siaga.

kehidupan (edisi kelima). Jakarta: Erlangga.

Kemenkes. 2010. Peraturan Menteri Kesehatan Republik Indonesia, No. 1464/MENKES/PER/X/2010.

Notoatmodjo, S. 2003. Pendidikan dan Perilaku Kesehatan. Jakarta: Rineka Cipta.

Robbins, Stephen P. 2001. Perilaku Organisasi Jilid I. Yogyakarta: Aditya Media.

Soetomo. 2006. Strategi-strategi Pembangunan Masyarakat. Yogyakarta: Pustaka Pelajar.

Syafrudin \& Hamidah. 2007. Kebidanan Komunitas. Jakarta: Buku Kedokteran EGC. 